\title{
ICT Impact in Iraqi Governmental Oil Companies
}

\author{
Ahmed Abbas Jasim Al-hchaimi ${ }^{1}$ \\ Electromechanical Systems Engineering Department \\ Southern Technical University \\ ThiQar Technical College ThiQar, Iraq \\ Email: ahmed.alhchaimi@stu.edu.iq \\ Ahmed Jamal Ibrahim² \\ Najaf \\ Email: alzubaedyahmed@gmail.com \\ Ahmed Ghanim Wadday ${ }^{3}$ \\ College of Electrical and Electronic Engineering Techniques \\ Middle Technical University \\ Baghdad, Iraq \\ Email: ahmadghw@atu.edu.iq
}

\begin{abstract}
This study tries to focusing on applying information communication technology for economic importance of Midland Oil Company (MDOC), which is among contemporary oil companies in Iraq. Since ICT forms a significant aspect of achieving organizational economic objectives, most of public and private bodies seek to utilize ICT tool and techniques to improve work efficiencies. The emerging growth in ICT has made it process and service automation possible in managing organizational activities. To determine this effect of ICT on organizations, this study formulated statistical research model at MDOC through using fifteen questionnaires which were distributed on three axes. The outcome of the questionnaire analysis revealed that there is inadequate comprehensive infrastructure to suitably support ICT within the selected organization management. Also, it revealed that there are no ideal standards to maintain and sustain internet networks. Based on these revelations, the study presents recommendation for the adoption of ICT with the aim of minimizing cost, enhancing communication and managing infrastructure. Also recommends the need to support IT department within an organization, with essential equipment, in terms of man and machine, for better efficiency to employ the key of ICT Impact in Iraqi governmental oil companies.
\end{abstract}

\section{Index Terms - ICT, MDOC, Pearson Linear Correlation Coefficient, Cronbach coefficient,}

\section{INTRODUCTION}

ICT is a platform that supports information sharing and interactive activities. These kinds of activities involve data collection, processing, storage, reporting and representing. The activities further consist of communication and collaboration, which are some of the benefits of ICT. And depends on indigenous value which represents how ICT is designed and managed [1]. The knowledge and management of available technology and its configuration varies from the concept of ICT from a different point of view. In ICT, there are sets of related tools and devices that are designed for specific tasks such as course delivery, publishing, or transaction processing. And these are collection of equipment organized for the usage in ICT. These are integrated components of information and communication in terms of tools, devices, practices and services that make it possible for the collection, processing, storage and sharing of information with other entities within a wider-range of system of individual. ICT is made up of devices and information that makes problem solving, learning and collaborative thinking possible. And it is significant aspect of workplace collaboration and information sharing.

\subsection{ReSEARCH METHODOLOGY}

Methodology is an important aspect of research which help understand the research problem better and proffer solution sign for the research objectives. The methodology considered in this study is as follows in terms of the research problem description, hypothesis and data collection tools and technique as well as statistical method of questionnaire analysis:

\section{2-2.1 RESEARCH PROBLEM}

Despite the known benefits and influence of modern and advanced ICT services at our disposal. People MDOC still use the traditional means of information and communication services. This spring up the current research problem of lack of application of ICT and best means of enabling its effect within Midland Oil Company. This inadequacy therefore reflected on the provided level of service and overall performance of the company.

\section{2-2. RESEARCH IMPORTANCE}

The importance of this study is based on the extent of development and the current evolvement of ICT, which characterized the creation of wide range of opportunities in various areas of our daily life such as domestic and workplace. The importance of this research is further perceived towards the involvement of ICT which contributes to the continuous development through information transfer and sharing amongst others. In the recent time, ICT has become the most significant support for marketing and services dissemination for organizations, for which Midland Oil Company is not an exception. ICT is most relevant and beneficial for simplifying and enhancing company operations. And this in turn enables effective communication, cost reduction and collaborative relationship among relevant departments within the organization. 
2-3. RESEARCH AIM

southwest with Jordan. Iraqi capital city is Baghdad and it's also the largest city in Iraq [2]. The country is surrounded by This research aims to explore and present understanding for the rodoastline of 36 miles ( $58 \mathrm{~km})$ on the Arabian Gulf in the north. of ICT as effective infrastructure that is significant for Midland OAlso, it includes the east area for the desert of Syria, the Company. The effective deployment of ICT is aimed to contribute morthwestern side of Zagros mountain chain and Mesopotamian the company growth to attain the level of competitiveness to strive Atluvial Plain. There are two major rives; Euphrates and Tigris both local and global stage.

\section{2-4. RESEARCH POSTULATE}

that runs through the south into Iraq down to the Shatt al-Arab close to the Arabian Gulf. The existence of the river gives Iraq For this research, there are three main theories that have be甲otentials for fertile land sign for for agricultural development. considered, they are; However, the economy of Iraq is heavily dependent on oil.

1. Statistically, there exists vital connection between management Efen though oil is the major economy, it is not the only oil facility and information technology in the development onomic potential compared to other Arabian Gulf countries.

infrastructure of the company departments.

2. There are substantial dependencies between the usage information technology and space availability as location for IT centers development.

3. The efficiency of oil organization management is significantly and statistically linked with information technology.

\section{2-5. STUDY LOCATION}

(i) Spatial: The research study location is based on a case of Midland Oil Company.

(ii) Human: In the case study are sample of 50 employees who work within administration and ICT department, selected for the purpose of this research study.

\section{2-6. RESEARCH TOOLS}

The tools involve in this research includes data collection methods which are theoretical and practical in nature.

(i) The theoretical tool consists of data and information gathered through related academic journals, books, existing published study and online sources. These are relied upon to formulate theoretical understanding of the research, including information of great values that be applied directly.

(ii) Practically, questionnaire was designed and used to obtain various perspectives from the sample size of 50 company employees. Their responses were then analyzed using the Fifth Likert Scale with the intention of generating results that would suggest solution to the problem of research interest.

\section{2-7. COMMUNITY OF RESEARCH SAMPLE}

The community of the current research sample are made up of skilled ThiOar Oil Company employees who have working knowledge and directly involve with information and communication technology, as well as those that are expert in administration role.

\section{2-8. STATISTICAL METHODS}

The response of the research questionnaires was analyzed using statistical methods such as Pearson Correlation Coefficient - simple, Mean, Standard Deviation and relative importance adopting SPSS version 23 as statistical analysis software.

\section{THEORETICAL FRAMEWORK}

\section{3-1. IRAQ ECONOMIC OVERVIEW}

Iraq is located in the western part of the continent of Asia with republican regime of government. It shares borders in the east with Iran, the north with Turkey, the west with Syria, the southeast with Kuwait, the south with Saudi Arabia, and the
In the year 1925, Iraqi became of the founding countries of OPEC, when it started producing oil to the rest of the world. Oil production started two year later in the field of Baba Gergir in Kirkuk before extending to other fields. Before nationalization in 1972, the oil franchising organizations adopted the policy of punishing Iraq through production reduction and limiting its international markets share. Particularly, after the $14^{\text {th }}$ July 1958 revolution and the enactment of 1961 Law No. 80 called the Direct Investment Law. Even though there was imposed ban on Iraq since 1990, the country still generated total incomes of approximately above 20 billion dollars as of year 2000, through oil exportation. Also, the daily production of oil per barrels amounting to minimum of 2 million, before the invasion of the United State. The capacity of the Iraq refinery is more than 500,000 barrels daily via the largest number of oil refineries of 12 compared to the rest of the Arabian Gulf, as of year 2000. In 1989 , the total income generated is equal to 14.5 billion dollars, which is made up of $99 \%$ of the oil exportations. Based on a 1990 survey, the oil export value of Iraq is equal to 10.535 billion dollars. This translates to 99.5 per cent of oil and energy sources, with $28 \%$ being the import share of the USA. However, the Iraqi oil exportation only accounted for two hundred and sixty nine million dollars in 1996 or one-on-three of Iraq's nine hundred fifty million dollars but its progress to more than fifteen billion dollars in 2001 of overall exports amount 15.94 billion dollars.

\section{3-2. ICT ROLE IN ORGANIZATIONS}

Information and Communication Technology (ICT) widely refers to the collective technical infrastructure of software, telecommunication and hardware. In most cases, it is simply called Information Technology (IT). In most organization, IT or ICT is seen as a significant tool for operational optimization as well as embarking on exchange of information. ICT can offer prevailing tools and strategic for organizations, which, if appropriately deployed and applied, could provide immense benefits in enhancing and consolidation competitive advantage [3]. One of the most important tasks of ICT is to enable communication and exchange of information in order to facilitate knowledge exchange among the different organizational and administrative functions. Where, ICT is relied upon as a tool for employees and customers networking and collaboration within an organization. This is because it removed hindrances to real-time communication and effective sharing of information [4]. ICT supports organizational transformation through combination of new technologies with business and society hereby allowing the development of recent discovery as well as knowledge [4]. 


\section{3-3. GOVERNMENTAL OIL COMPANIES IN IRAQ}

There are four major Governmental corporations for oil in Iraq; they are Oil Companies of ThiQar, Midland, North and Basra. Among them all, Midland Oil Company (MDOC) is the focus in this research study. This is because it is the newest being established on the $1^{\text {st }}$ of April 2017, with huge potential of making it a modern company that develops within the oil sector through the use modern technologies such as ICT. In terms of

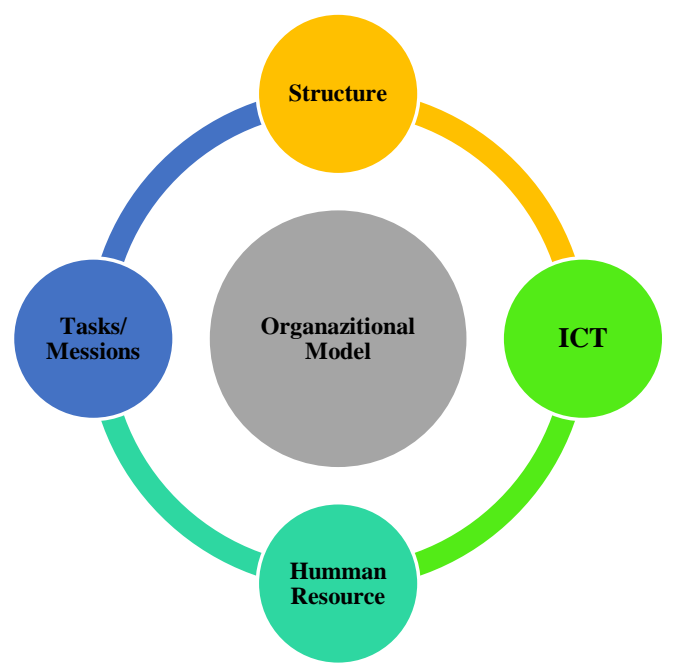

Fig. 1: Organization Model

proximity, the geographical location of the company makes it an easy choice for research consideration.

\section{3-4.ORGANIZATIONMODEL}

The theoretical model applied in this research relates to an organization structure which comprises of four components that are inter-related. As illustrated in Figure 1, these four components. are task, structure, technology and people. The structure of an organization depicts system of workflow, communication and authority. Organization's strategy refers to the course of action of the fundamental long haul destinations for an association. And the duty Also provision from claiming assets will strategy anticipated with accomplishes association targets. People within an organization refer to working individuals while technology refers to the tools, techniques as well as actions required to convert inputs to outputs in an organization. It is established that if any of the component of the organization model changes, the other three must change. The fate of an organization is characterized and determined through the interaction of these four components. The model has been selected in this research because it involves many crucial matters that are pointers to complete understanding of the interaction between organization and ICT. In this study, however, the impact of ICT on the organization is been focused, which is and only the engineering element, What's more authoritative offers.

\section{3-5. ICT EFFECT ON OIL OPERATIONS INCREASING}

In oil and gas, upstream operations refer to crude oil exploration and production. The main worry of this operation is the means of extending the lifespan of crude oil reserves with the intention of continuously meeting increasing demand for oil. The problem being faced by the upstream sector is the increase in the production of oil as well as improvement of its recovery rate. For this reason, the Multinational Oil Companies (MNOCs) is prompted to invest more in research and development, for which the development of improved drilling and extraction technologies have been achieved [5.

\section{APPLIED FRAME OF RESEARCH}

\section{4-1. APPROACH SAMPLING}

All 50 employees' sample of Midland Oil Company received the questionnaire, and all questionnaires were retrieved completely. The questionnaire was dispersed based on three main topics of concern; 1) the importance of applying ICT for oil facility management; 2) the scope of oil facility support through the implementation of ICT and; 3 ) the infrastructure availability for the progression of ICT in the stated organization.

\section{4-2. MDOC EMPLOYEES QUALIFICATIONS SAMPLE}

Figure 1 is shown the competence of MDOC human resource

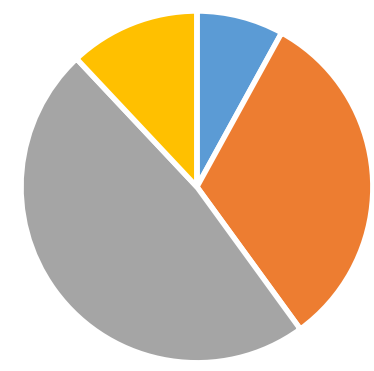

- 1 Secondary $4 \quad$ - 2 Diploma $16 \quad$ - 3 BSc 24

those related to our research as well as Figure 2 is son the number of employment years :

Fig. 2: Employees Competence

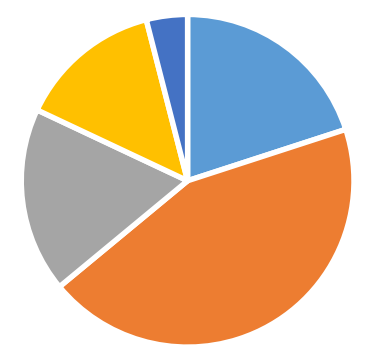

$$
\text { -15-Jan }=25-10 \quad=3 \quad 10-15
$$




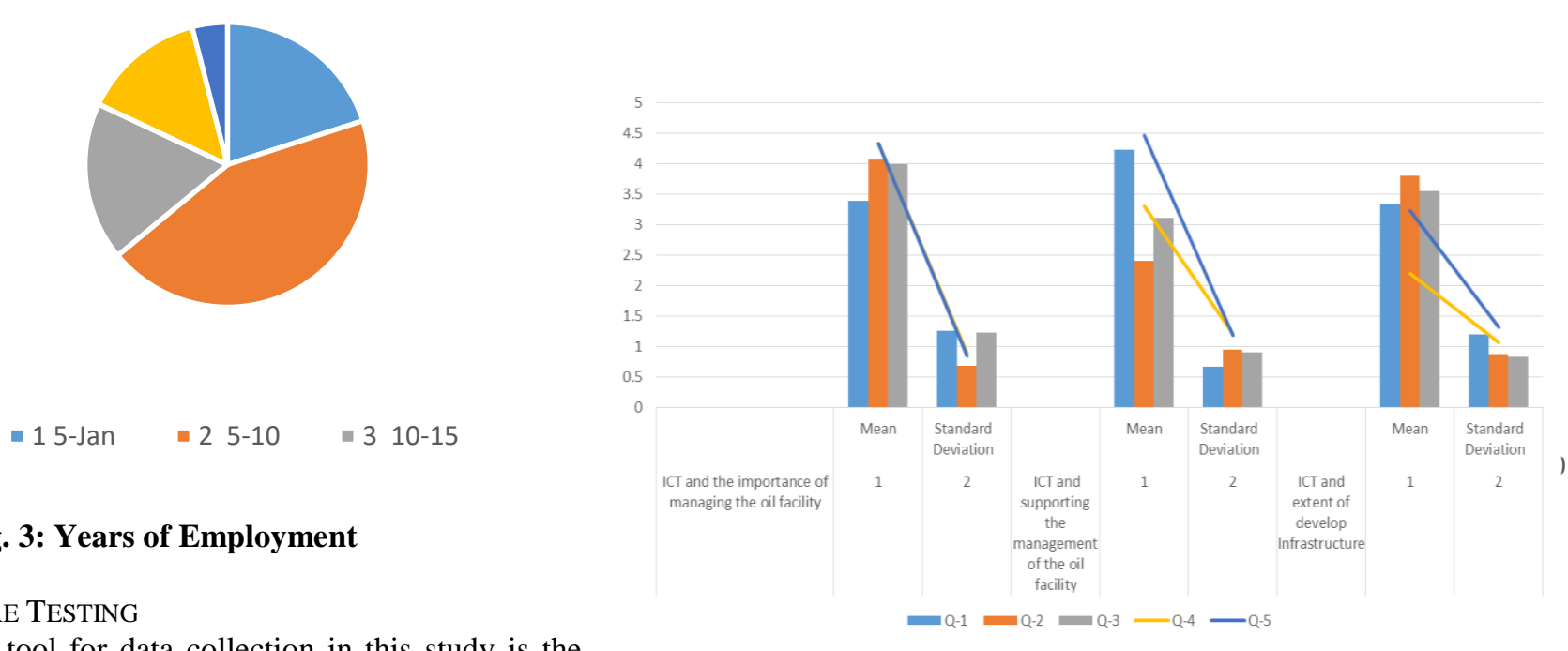

\section{4-3. QueSTIONNAIRE TESTING}

The main research tool for data collection in this study is the questionnaire, which has been designed and depends on Fifth Likert Scale, from (Absolutely agreed up to Not Agree). However, to ensure data accuracy and integrity, below are group of tests that has been considered.

\section{4-4. THE REALty OF MEASURING ToOL}

Through the use of Alpha Test Cronbach;s,:The construction reliability of the study testing tool was verified and the stability coefficients were determined for the Testing Tool utilizing the Alpha Test Cronbach as shown in Figure 3.

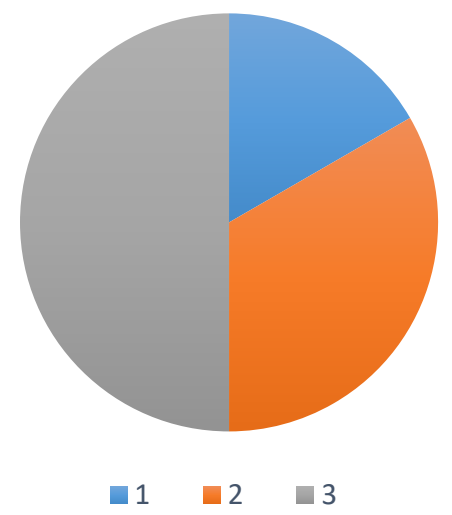

1. Importance in spun

2. Enhancing the spun

3. Scope of Infrastructure Developing

\section{Fig.5: Variables of research}

\section{4-5. RESEARCH VARIABLES}

Figure 4 describes of the mean and standard deviation of testing tool in a varied metrics.In this way, coming up next were conclude dependent on Figure 4 demonstrates both ward (ICT and the significance of dealing with the oil office) and additionally autonomous (ICT) factors. The mean esteem extended between two factors 3.38 and 4.32 on scale of Likert that connote which there is relationship from

Fig. 4: Alpha - Cronbach binding coefficient for search variables

the example of the exploration with defense. The standard deviation is decreased between 0.84 and 1.25 in an absolutely worthy pattern, and whole conditions were higher than the mode of the territory test (3) with deference for the other factor (ICT and assisting the administration of the oil office). The rate

of the arithmetical midpoints extend from the value 2.9 to the value 4.22 toward concede to - Liquart pentacle scale which exhibits that a relationship for the example of the exploration with avocation. For the reliant variable (ICT and degree of create Infrastructure), the estimations of the arithmetical midpoints went between 2.20 and 3.8 with standard deviation from 0.83 to 1.20 toward Indifferent on - scale of Likert and it demonstrates an unbiased nearness of the examination test.

\section{4-6. Test Postulates of Research}

Scientists were dependence on Pearson Linear Correlation Coefficient to examine the theories described by the connection between ICT (an Independent variable) and both of (ICT and the significance of dealing with the oil office), (ICT and assisting the administration of the oil office and ICT and degree of create Infrastructure) as a variable of reliant. Tables nombers $(5,6,7)$ demonstrate the Pearson Linear Correlation Coefficient Matrix, among factors. In addition, the fig. has been alluded to the 50 representatives test measure and the sort of choice. Additionally, the utilization of SPSS Software is essential, and the tables likewise are demonstrating the association. Therefore, if the outcome see $(*)$ for the Correlation Coefficient implies moral connection.

FIRST Postulate: Figure 5 approves of the first hypothesis validity which there is the positive and strong correlation between ICT and the management of oil facility.

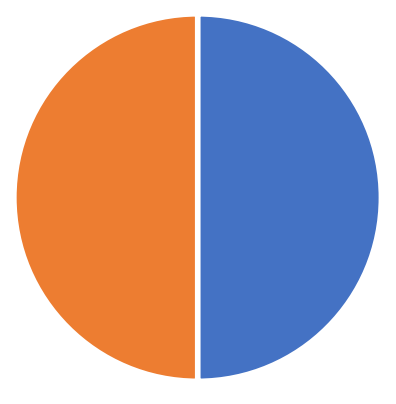

- ICT 1 -- $500.0950 * * 0$

- Importance of managing the oil facility $0.0950 * * 10501$--

Fig.6: ICT and Managing Importance Relations 
Where $(* *)$ is Correlation. The Figure 5 uncovers a positive and solid relationship network because of more than $(0.50)$ between significance of dealing with the oil office and ICT, where the Pearson Linear Correlation coefficient is outlined $(0.95 *)$ and result for bolster the exact of the primary theory tells that there is a connection with factual centrality among ICT and dealing with the facility of oil] and the esteem is Sig $=0.00$ precise.

SECOND Postulate: The second hypothesis is confirmed by Fig.6, where it has been calculated that there is a link between technology of information and providing oil facility management. Figure 6 demonstrates the relationship framework between free factor (ICT) and ward ICT variable ( an Independent variable) and both of (ICT and the significance of dealing with the oil office, (ICT and supporting the administration of the oil office and ICT and degree of create Infrastructure) as a needy variable. Where it is insignificant and that support the Second Hypothesis, where it's enrolled an esteem $(0.886 * *)$ at a dimension of centrality (0.05) and that affirm the Second theory and that tells [there is a connection with Statistical essentialness between research factors.

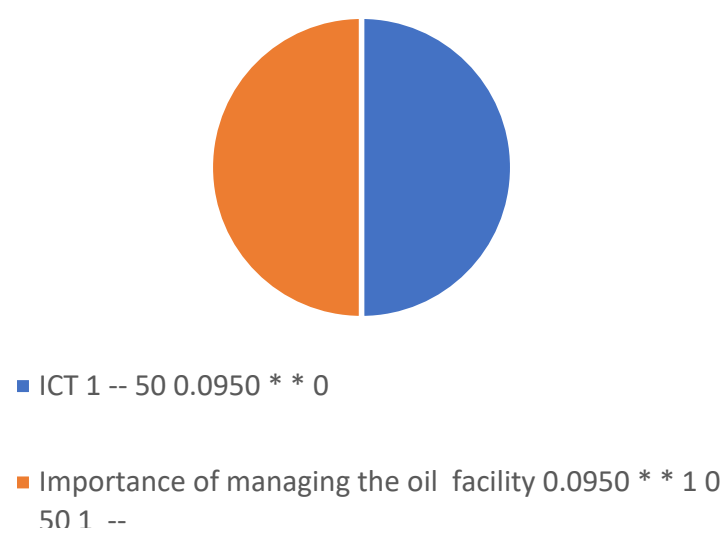

Fig. 7: Managing Oil Facility Importance

$>$ ThIRD Postulate: Supporting for administration of the facility and ICT and the degree of Infrastructure growth correlations are demonstrated by Figure 7, where it is enrolled the rate of $0.891 * *$ at the rate of significance $(0.00)$ and which agree with the Third Hypothesis which determines [A statistical significance correlation between research variables and confidence interval is 95\%] .

\section{Fig.8: Relation of ICT and infrastructure developing scope}

\section{CONCLUSIONS}

By analyzing the results obtained, we can include some [7] conclusions. Firstly, Information and Communication Technology imply to expanding rivalry among enterprises. As well the high quality standards that support the networks and the Internet at the oil facility are almost nonexistent. Disregarding of utilizing an ICT is expanding the financial outlay. The staff of Midlinad Oil Company does not rely on e-mail or electronic conferences in organizing administration matters. A prevailing opposition in the organization to backing the utilization of an ICT and standard applications. Finally, Information and Communication Technology achieves a concentrated dominate of the organization and remote administration.

\section{RECOMMENDATIONS}

The management of the company should give more attention for both ICT in analogous for the attention to human resources and infrastructure. Also, it should also urge its employees to use modern communications systems and the Internet to achieve their jobs. Midland Oil Company should be adopt and utilize the optimal utilization of an ICT with standard applications as well e-mails and conference. MDOC must be supplied the system of active networks, and effective service providers for Internet to actualize the criteria for the utilization ICT and its developed applications. Affirmation on utilize an ICT for diminishing financial disbursement.

\section{REFERENCES}

[1] Rebecca Angeles, "Using the Technology-Organizati Environment Framework and Zuboff's Concepts Understanding Environmental Sustainability and RFID: T Case Studies," International Journal of Economics : Management Engineering, Vol:7, No.11, 2013, pp. 2878- 28

[2] Marion Farouk-Sluglett and Peter Sluglett, "The Historiograr of Modern Iraq," Oxford University Press on Behalf of American Historical Association Vol. 96, No. 5. Dec. 1991, 1408-1421, doi: 10.2307/2165278.

[3] Luay Anaya, Mohammed Dulaimi, Sherief Abdallah, "An Investigation into the Role of Enterprise Information Systen in Enabling Business Innovation," Business Process Management Journal, Vol. 21 Issue: 4, 2015, pp.771-790, https://doi.org/10.1108/BPMJ-11-2014-0108.

[4] Michael H. Morris, Donald F. Kuratko, Jeffrey G. Cor "Corporate Entrepreneurship and Innovation," South West CENGAGE Learning, $3^{\text {rd }}$ Edition, 2016.

[5] Shamsuzzoha, A., Ferreira, F., Faria, J., Azevedo, A., Hao, \& Helo, P. , "Virtual enterprise management: Perspective Process-Based Business Collaboration," IEEE, Internatio Conference on Industrial Engineering and Engineer Management, Hong Kong, (10-13) December 2012, c 10.1109/ieem.2012.6838102.

[6] Brynjolfsson, E., \& Saunders, A.,"Wired for Innovation: H information Technology is Reshaping the Econom Massachusetta Institute of Technology, 2010.

Alberto Bayo-Moriones and Fernando Lera-López, "A Fi1 Level Analysis of Determinants of ICT Adoption in Spai Elsevier, Technovation, Vol. 27, Issues 6-7, June-July 20 Pages 352-366, doi.org/10.1016/j.technovation.2007.01.003 
[8] Cardona, M., Kretschmer, T., \& Strobel, T., "ICT ‘ [10] productivity: Conclusions from the Empirical literati Information Economics and Policy," Vol. 25, Issues 3, 20 pp.109-125.

[9] Tran, Q., Zhang, C., Sun, H., \& Huang, D., "Initial Adopt [11] Versus Institutionalization of E-Procurement in Construct Firms: An Empirical Investigation in Vietnam" Journal Global Information Technology Management, Vol. 17, Iss 2, 2014, pp. 91-116.
Hall, B. H., Lotti, F., \& Mairesse, J., "Evidence on the Imp of R\&D and ICT Investments on Innovation and Productiv in Italian Firms. Economics of Innovation and $\mathrm{N}$ Technology," Vol. 2, Issues 3, 2017, 300-328.

Yan Yu, Xiao-Ying Dong, Kathy Ning Shen, Mohan Khalifa and Jin-Xing Hao "Strategies, Technologies, ‘ Organizational Learning for Developing Organizatio Innovativeness in Emerging Economies," Journal of Busin Research, Vol. 66, Issues 12, 2013, pp. 2507-2514. 